Case Report and Review of the Literature

\title{
Painless Peri-Tonsillar Abscess in a Pediatric Patient: Case Report and Review of the Literature
}

\author{
Christopher Jabbour and Randa Barazi* \\ Department of Otorhinolaryngology Head and neck surgery-American University of Beirut Medical Center, Beirut, Lebanon
}

\begin{tabular}{|c|c|}
\hline A R T ICLE INFO & A B S T R A C T \\
\hline Article history: & Crohn's disease is an immune mediated inflammatory disease that affects the gastrointestinal tract anywhere \\
\hline Received: 23 March, 2020 & from the oral cavity proximally, to the anus distally. A large number of patients with Crohn's disease may \\
\hline Accepted: 15 April, 2020 & present with a multitude of oropharyngeal manifestations, such as mucositis, granulomas and ulcerations. \\
\hline Published: 18 April, 2020 & Infliximab, a monoclonal antibody that binds to $\mathrm{TNF} \alpha$, is a treatment modality used in the management of \\
\hline Keywords: & Crohn's disease. $10 \%$ to $30 \%$ of patients with Crohn's disease develop intra-abdominal abscesses in the \\
\hline Crohn's & course of the disease, a finding that is much less common in oropharyngeal manifestations. We herein \\
\hline Infliximab & present the case of a painless peri-tonsillar abscess in a patient with Crohn's disease maintained on \\
\hline Peri-tonsillar abscess & $\begin{array}{l}\text { infliximab that required surgical drainage as means of treatment. To our knowledge, this is the first case } \\
\text { demonstrating such a finding in a patient that is maintained on infliximab. }\end{array}$ \\
\hline
\end{tabular}

(C) 2020 Randa Al Barazi. Hosting by Science Repository.

\section{Case Report}

A 7-year-old female patient with a history of Crohn's disease diagnosed in March 2018 and maintained on infliximab for 2 months $(5 \mathrm{mg} / \mathrm{kg} / \mathrm{month})$, presented to the ER for a 5-day history of trismus and right mouth deviation with jaw opening. She was scheduled for her third dose of infliximab 3 days prior to presentation, but treatment was postponed due to findings of a single episode of low-grade fever $38^{\circ} \mathrm{C}$ and a resolved odynophagia, suggestive of viral upper respiratory tract infection. Rapid strep test was done at that time and was negative. She denies a history of rhinorrhea, postnasal drip, chills, dysphagia, cough, and TMJ dislocation, but reports a history of possible left soft palate bulge 1 year ago, that resolved spontaneously with fluid outflow into the oral cavity, suspicious of left ruptured peritonsillar abscess.

Vital signs on presentation were unremarkable; Heart rate was $98 \mathrm{bpm}$, BP $116 / 75 \mathrm{mmHg}$, and temperature $36.9^{\circ} \mathrm{C}$, knowing that no antipyretics were given at home. On physical examination of the oral cavity, no soft palate bulge was seen, the uvula was midline, the tonsils were non erythematous, non-edematous and non-exudative, however a discrepancy in their size was observed, with a grade 3 tonsil on the left, and a grade 1 on the right. Right mouth deviation was observed only with jaw opening, with no TMJ dislocation palpated or tenderness. Laboratory investigations revealed a white blood cell count of 8600 /cu.mm, PMN $46 \%$, along with an erythrocyte sedimentation rate of 23 $\mathrm{mm} / \mathrm{hr}$, and C reactive protein of $22 \mathrm{mg} / \mathrm{L}$. A decision was then taken to subject the patient to a CT scan of the neck with IV contrast, which revealed a $1.4 \times 1.6 \times 1.7 \mathrm{~cm}$ left peritonsillar abscess (Figure 1). Her case was reviewed with her gastroenterologist and her pediatrics infectious disease physician, who agreed to a diagnosis consistent with infliximab instigated painless peritonsillar abscess.

The patient was then started on ceftriaxone $75 \mathrm{mg} / \mathrm{kg} / \mathrm{day}$ and clindamycin $40 \mathrm{mg} / \mathrm{kg} / \mathrm{day}$. After a multidisciplinary meeting, the gastroenterologist did not want to delay the infliximab treatment while waiting for the IV antibiotics to take effect, so the decision was made to take the patient down to the operating room the next day, where the otolaryngologist performed a left tonsillectomy and evacuation of left

${ }^{*}$ Correspondence to: Randa Al Barazi, M.D., F.A.C.S., Assistant Professor, Department of Otolaryngology- Head and Neck Surgery, American University of Beirut Medical Center, 11 0236, Riad el Solh, Beirut 1107 2020, Beirut, Lebanon; Tel: 9611350000; Ext: 5477; Fax: 9611370793; E-mail: ra110@aub.edu.lb

(C) 2020 Randa Al Barazi. This is an open-access article distributed under the terms of the Creative Commons Attribution License, which permits unrestricted use, distribution, and reproduction in any medium, provided the original author and source are credited. Hosting by Science Repository. http://dx.doi.org/10.31487/j.JSO.2020.02.04 
peritonsillar abscess. Intraoperative cultures, gram stain and blood cultures were all negative, however, bacterial identification by 16S DNA sequencing yielded Fusobacterium nucleatum. The left tonsillar specimen was sent to pathology and was consistent with follicular lymphoid hyperplasia, $3 \times 2 \times 1.5 \mathrm{~cm}$ in size.

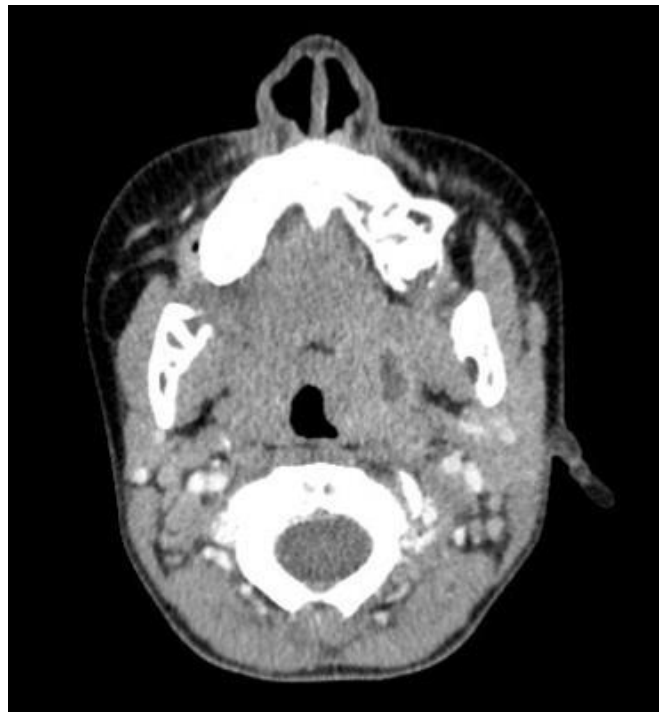

Figure 1: Left peri-tonsillar abscess with rim enhancement.

Post operatively the patient had a resolved trismus and recovered smoothly without any complications. The mouth deviation, however, was still present, and the patient was discharged on post-operative day 5 and asked to follow up with otolaryngology. Follow up in clinics one month later showed complete resolution of the mouth deviation.

$10 \%$ to $30 \%$ of patients with Crohn's disease will develop abdominal or pelvic abscesses during the course of their illness, originating from micro-perforations and inflammatory changes of the affected bowels, eventually requiring medical, image guided, or surgical therapy [1]. Oropharyngeal manifestations of Crohn's disease have been first described in 1969 by Dudeney et al. [2]. Affected patients might present with lip or buccal swelling, ulcerations, angular cheilitis, cobblestoning, granulomatosis, and gingival hyperplasia [3, 4]. Currently, there are no studies in the literature that describe painless peritonsillar abscess, let alone in patients with a history of Crohn's disease.

Infliximab is a monoclonal antibody that binds to TNF $\alpha$, one of the major pro inflammatory cytokines, decreasing its endogenous activity in the body. In Crohn's disease, its onset of action is at 8 to 12 weeks, possesses a half-life of 7 to 10 days and has a duration of action extending over several months [5]. To our knowledge, infliximab has not been previously associated with the formation of peritonsillar abscesses, however it has been reported by Nithianandan $e t$ al. as a causative agent for a large paraspinal abscess extending to the epidural space in one of the patients with a history of Crohn's disease. [6].
On the other hand, Bao et al., reported a case of an 18-year-old lady with advanced Crohn's disease that presented with a flare up of her condition and bilateral tonsillitis with intratonsillar abscess formation, that improved on infliximab infusion, achieving complete resolution over a period of 5 months [7]. In addition, tonsillar granuloma as a manifestation of Crohn's disease was identified by Turchi et al. in a previously undiagnosed patient with positive findings on colonoscopy and biopsy [8]. Cardoso et al. also described the treatment of oropharyngeal Crohn's disease with infliximab. [9]. We postulate that due to its anti-inflammatory effects, infliximab incited a painless peritonsillar abscess, and that the patient was unlikely to improve without surgical intervention, knowing the nature of the pathology stated and the subsequent risks it poses.

\section{Conclusion}

In conclusion, patients with oropharyngeal manifestations of Crohn's disease should be carefully evaluated and assessed, and the treatment should be tailored according to the patients' condition, taking into consideration the medication used for disease maintenance and its potential side effects.

\section{REFERENCES}

1. Richards RJ (2011) Management of abdominal and pelvic abscess in Crohn's disease. World J Gastrointest Endosc 3: 209-212. [Crossref]

2. Dudeney TP (1969) Crohn's disease of the mouth. Proc R Soc Med 62: 1237. [Crossref]

3. Scully C, Cochran KM, Russell RI, Ferguson MM, Ghouri MA et al. (1982) Crohn's disease of the mouth: an indicator of intestinal involvement. Gut 23: 198-201. [Crossref]

4. Mergulhã oP, MagroF, PereiraP, Correia R, Lopes JM et al. (2005) Gingival hyperplasia as a first manifestation of Crohn's disease. Dig Dis Sci 50: 1946-1949. [Crossref]

5. Klotz U, Teml A, Schwab M (2007) Clinical pharmacokinetics and use of infliximab. Clin Pharmacokinet 46: 645-660. [Crossref]

6. Nithianandan N, Loftus MJ, Johnson PD, Charles PG (2019) Large paraspinal abscess as a complication of infliximab therapy in Crohn's disease. BMJ Case Rep 12: e227665. [Crossref]

7. Bao B, Harriott M, Kroeker KI (2017) Healing of Tonsillar Crohn's Disease With Infliximab. Clin Gastroenterol Hepatol 15: A31-A32. [Crossref]

8. Turchi RM, Soriano H, Rodgers GL (2006) Tb or not TB: Crohn's disease presenting with tonsillar granulomas. Otolaryngol Head Neck Surg 134: 528-530. [Crossref]

9. Cardoso H, Nunes AC, Carneiro F, Tavarela Veloso F (2006) Successful infliximab therapy for oral Crohn's disease. Inflamm Bowel Dis 12: 337-338. [Crossref] 